\title{
Effects of dexmedetomidine on heart rate control and pre-operative outcome in patients with acute aortic dissection: a propensity-matched analysis
}

\author{
Sheng-Long Chen ${ }^{1}$, Yun-Fei Chai ${ }^{2}$, Zhong-Hua Wang ${ }^{3}$, Xin-Qiang Liu ${ }^{1}$, Hong-Guang Ding ${ }^{1}$, \\ Hong-Ke Zeng ${ }^{1}$ \\ ${ }^{1}$ Department of Critical Care Medicine, Guangdong Provincial People's Hospital, Guangdong Academy of Medical Sciences, Guangzhou, China; \\ ${ }^{2}$ Anesthesiology Department of Guangdong Cardiovascular Institute, Guangdong Provincial People's Hospital, Guangdong Academy of Medical \\ Sciences, Guangzhou, China; ${ }^{3}$ Department of Gerontological Critical Care Medicine, Guangdong Provincial People's Hospital/Guangdong Academy \\ of Medical Sciences/Guangdong Provincial Geriatrics Institute, Guangzhou, China \\ Contributions: (I) Conception and design: HK Zeng, SL Chen; (II) Administrative support: YF Chai; (III) Provision of study materials or patients: XQ \\ Liu; (IV) Collection and assembly of data: ZH Wang, XQ Liu; (V) Data analysis and interpretation: HG Ding; (VI) Manuscript writing: All authors; \\ (VII) Final approval of manuscript: All authors. \\ Correspondence to: Hong-Ke Zeng, MD, PhD. 106 Zhongshan Er Road, Guangzhou 510080, China. Email: zenghongke@tom.com.
}

Background: The total survival rate in patients with acute aortic dissection (AAD) has been greatly improved because of surgical technique advances. However, the pre-operative mortality rate remained high. In this study, we sought to evaluate the effects of dexmedetomidine (DEX) on heart rate control and preoperative outcome in AAD.

Methods: Retrospectively enrolled 461 patients who were diagnosed with AAD during the first 7-day after admission and divided into two groups according to the use of intravenous DEX: DEX group (91 patients) and Control group (370 patients). The heart rate and systolic blood pressure (SBP) level in both groups were recorded, and the incidence of aortic dissection rupture and pre-operative survival rates within 7 days were considered as the primary clinical outcomes.

Results: Compared to the Control group, heart rate of DEX group in the early 3 hours was significantly higher $(\mathrm{P}=0.009)$, and the 24-hour heart rate fluctuation was smaller $(\mathrm{P}=0.012)$. There was no difference in the systolic blood pressure (SBP) between the two groups, but the 24-hour fluctuation of SBP in DEX group was less $(\mathrm{P}=0.003)$. We performed a propensity-matched analysis to minimize selection bias and found that there were 7 (7.9\%) patients in the DEX group occurred acute pulmonary edema, 17 (19.1\%) patients in the Control group $(\mathrm{P}=0.047)$. And the pre-operative survival rates within 7 days were significantly improved in DEX group $(\mathrm{P}=0.004)$.

Conclusions: DEX can be beneficial to facilitate heart rate control, keep SBP more steady, and reduce the incidence of pre-operative aortic rupture in patients with AAD.

Keywords: Acute aortic dissection (AAD); pre-operative; heart rate; dexmedetomidine (DEX)

Submitted Feb 10, 2020. Accepted for publication Jul 31, 2020.

doi: 10.21037/apm-20-363

View this article at: http://dx.doi.org/10.21037/apm-20-363

\section{Introduction}

Acute Aortic dissection (AAD) is a life-threatening condition and intensive control of heart rate and blood pressure are vital to prevent the occurrence of aortic dissection rupture $(1,2)$. In recent years, the total mortality of aortic dissection has declined significantly along with advances of surgical technique (3). However, the incidence of pre-operative aortic dissection rupture remains high, as much as $36-72 \%$ patients would die within 48 hours after 
the onset of $\mathrm{AAD}$, and slow progress in drug treatment for heart rate control is one of the leading causes $(4,5)$. To date, the methods of heart rate control for AAD are mainly depending on large dosage of negative inotropic $\beta$-receptor blocker, which could simultaneously lead to serious complications including acute heart failure and pulmonary edema, particularly for the patients with preexisting heart dysfunction (6). Therefore, exploring new methods to control heart rate effectively accompanied with less complication is of great significance in reducing preoperative aortic dissection rupture.

Dexmedetomidine (DEX) is a selective alpha-2 adrenergic receptor agonist that exhibits sedative, analgesic, anxiolytic, and sympatholytic effects with minimal respiratory-drive depression (7). Despite bradycardia is a common adverse effect of DEX, that's exactly what AAD patients need, for whose heart rate should be controlled as slowly as possible under the premise of guaranteeing organ perfusion (8). During our clinical practice, we found that the heart rate in patients who received DEX infusion were under better control. To the best of our knowledge, there is no relevant study to address the use of DEX in ADD patients. Therefore, our study was conducted to describe the effects of DEX on heart rate control and pre-operative outcome among AAD patients.

We present the following article in accordance with the STROBE reporting checklist (available at http://dx.doi. org/10.21037/apm-20-363).

\section{Methods}

\section{Patients and DEX Administration}

This was a single center, retrospective and observational study. Patients who were admitted for AAD between January 2016 and June 2019 were identified as cases. This study was conducted in accordance with the Declaration of Helsinki (as revised in 2013) and was approved by ethics commissions of the First Hospital of Lanzhou University (No. GDREC2018162H), with a waiver of written informed consent. Exclusion criteria: aortic dissection rupture and pulmonary edema at the day of admission, bradycardia with heart rate $<55 \mathrm{bpm}$, hypotension with systolic blood pressure (SBP) $<90 \mathrm{mmHg}$, undergoing surgical treatment within two days after admission.

After hospital admission, DEX was administered at the discretion of the physician caring for the patient. Patients were divided into DEX group who received intravenous administration of DEX and Control group who did not receive DEX during hospitalization. Both groups accepted standard treatment according to Guidelines on the diagnosis and treatment of aortic diseases (8), including ECG monitoring, absolute bed rest, analgesia. Diltiazem, urapidil, nicardipine and sodium nitroprusside were used to control blood pressure and the target SBP is $100-120 \mathrm{mmHg}$ or lower; Esmolol was applied for heart rate control and the target heart rate is $60-70 \mathrm{bpm}$ or lower. In DEX group, based on the standard treatment, intravenous administration of DEX was started in the emergency department within $1 \mathrm{~h}$ of hospitalization with loading injection of $1 \mu \mathrm{g} / \mathrm{kg}$, followed by continuous infusion of $0.1-0.7 \mu \mathrm{g} /(\mathrm{kg} \cdot \mathrm{h})>2$ days.

The following baseline data were collected at admission: demographics (age, sex, smoking, basic diseases (hypertension, diabetes, hyperlipidemia, ischemic heart disease, cerebrovascular Disease), Acute Physiology and Chronic Health Evaluation (APACHE) II score, Left ventricular ejection fraction (LVEF), baseline $\mathrm{N}$-terminal pro-Brain Natriuretic Peptide (NT-pro-BNP), classification of aortic dissection (Stanford), heart rate and SBP, etc.

\section{Main outcome measures}

The heart rate and SBP level of both groups were recorded at $0 \mathrm{~h}$ (T0), $1 \mathrm{~h}(\mathrm{~T} 1), 3 \mathrm{~h} \mathrm{(T3),} 6 \mathrm{~h}$ (T6), $12 \mathrm{~h}$ (T12), $24 \mathrm{~h}$ (T24) and $48 \mathrm{~h}$ (T48) after admission. And the $24 \mathrm{~h}$ fluctuation of heart rate and SBP were measured respectively, which defined as: $24 \mathrm{~h}$ fluctuation range $=$ (daily maximum value - daily minimum value), represented by $\triangle$ heart rate- $24 \mathrm{~h}$ or $\triangle \mathrm{SBP}-24 \mathrm{~h}$. The average daily dosage of Esmolol was calculated and the occurrence of acute pulmonary edema was recorded.

During the 7-day observation, the incidence of aortic dissection rupture and pre-operative survival rates within 7 days were considered as the primary clinical outcomes of this study. Aortic dissection rupture was defined as a sudden sharp decline in heart rate and blood pressure leading to respiratory and cardiac arrest, and bedside ultrasound suggested new pleural and peritoneal effusion.

\section{Statistical analysis}

Data are the mean \pm standard deviation, percentages, or medians (interquartile range). Continuously variables were expressed as mean \pm standard deviation, categorical variables were expressed as number and percentage. The unpaired $t$-test or Mann-Whitney test was used for unpaired 
Table 1 Baseline characteristics of patient cohort

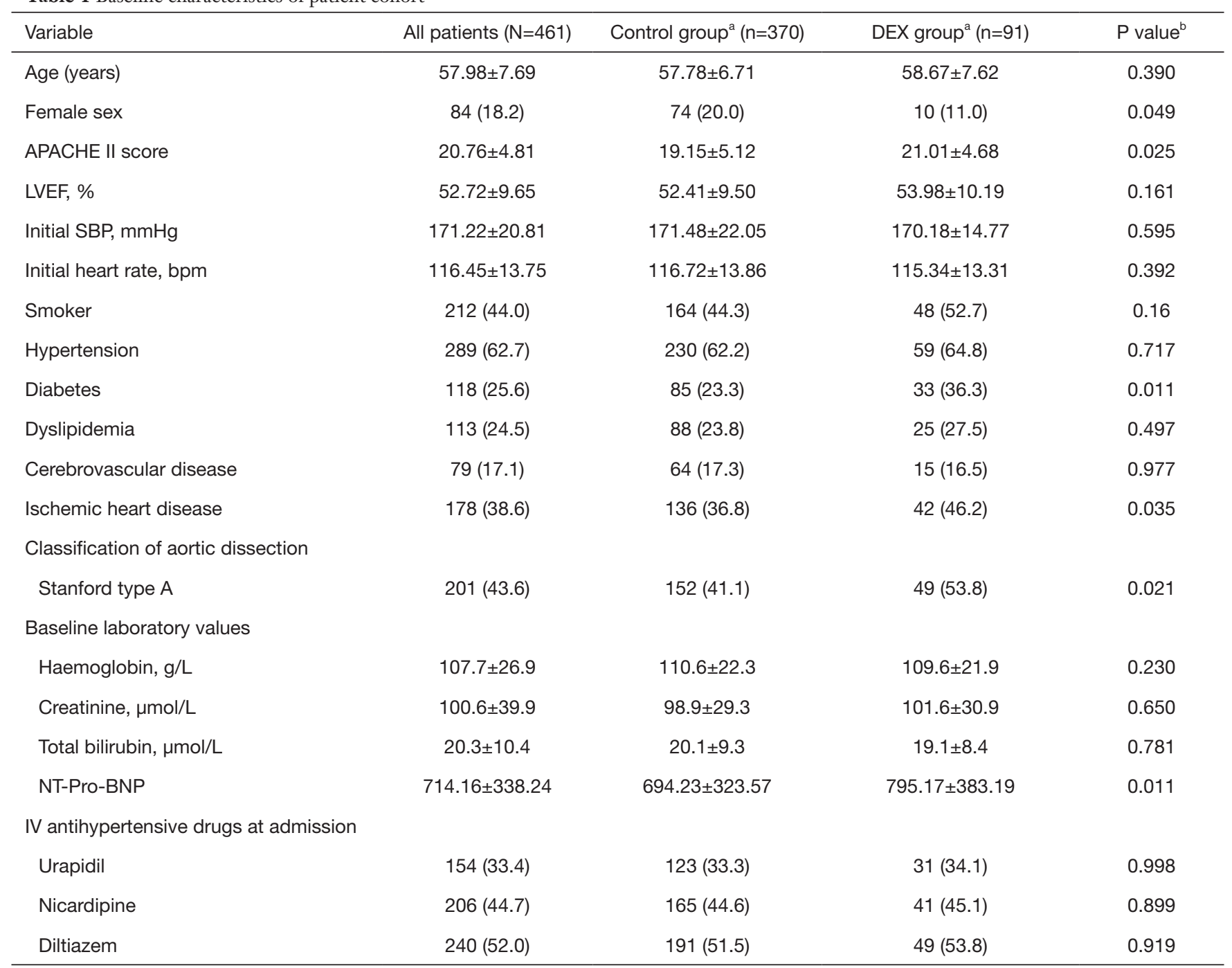

Continuous variables were expressed as mean \pm SD and categorical variables were expressed as $n(\%)$. ${ }^{a}$, DEX group was defined as patients treated with dexmedetomidine infusion, and Control group was the patients who didn't treat with dexmedetomidine infusion. ${ }^{b}$, $\mathrm{P}$ for global comparisons among groups by Kruskal-Wallis and chi-squared tests for continuous and categorical variables, respectively. APACHE II, acute physiology and chronic health evaluation II score; LVEF, left ventricular ejection fraction; NT-pro-BNP, N-terminal pro-brain natriuretic peptide; SBP, Systolic blood pressure.

comparisons as appropriate. The Fisher's exact or chi-square test was used to examine differences between categorical variables. The cumulative incidence of death was estimated according to the Kaplan-Meier method, and the log-rank statistic was used for comparisons.

After the data were initially analyzed, we performed a propensity-matched analysis to minimize selection bias. Based on a multivariate logistic regression model, each patient was assigned a propensity score. Covariates in the model included age, sex, comorbidities, APACHE II score, LVEF, NT-pro-BNP, classification of aortic dissection (Stanford), heart rate and SBP at baseline (Table 1). Patients in the DEX and Control groups were matched by 2-digit in a 1:1 ratio, based on the estimated propensity score for treatment with intravenous DEX. $\mathrm{P}<0.05$ was considered significant. All statistical data were analysed by licensed IBM SPSS Statistics version 24.0 for Windows (SPSS Inc, Chicago, IL, USA). 
Table 2 Multivariate Cox hazard regression analysis of 7-day mortality

\begin{tabular}{lccc}
\hline Variables & HR & $95 \% \mathrm{Cl}$ & P value \\
\hline Initial heart rate & 6.866 & $3.236-17.300$ & $<0.001$ \\
Initial SBP & 4.551 & $2.161-11.910$ & 0.011 \\
Stanford type A & 3.866 & $1.382-10.227$ & $<0.001$ \\
APACHE II score & 4.216 & $3.161-15.910$ & 0.002 \\
Fluctuation of heart rate & 4.341 & $3.161-16.910$ & $<0.001$ \\
Fluctuation of SBP & 4.941 & $2.019-12.981$ & 0.002 \\
Dexmedetomidine & 0.786 & $0.461-0.910$ & $<0.001$ \\
\hline
\end{tabular}

HR, hazard ratio; $\mathrm{Cl}$, confidence interval; APACHE II, acute physiology and chronic health evaluation II score; LVEF, left ventricular ejection fraction; NT-pro-BNP, N-terminal pro-brain natriuretic peptide; SBP, systolic blood pressure.

\section{Results}

\section{Demographics}

A total of 461 patients with AAD were finally included in our analysis: 91 patients in the DEX group and 370 patients in the control group. Fourteen patients (13.3\%) from the DEX group and 49 patients (12.5\%) from the control group were excluded according to the exclusion criteria.

Table 1 showed the baseline clinical characteristics of all participants. There was no statistical significance in part of baseline demographics (median age, smoking, hypertension, hyperlipidemia, cerebrovascular, LVEF, heart rate and SBP at admission) between the two groups. The prevalence of diabetes mellitus and ischemic heart disease was significantly higher in the DEX group. The percentage of female patients $(11.0 \%$ vs. $20.0 \%, \mathrm{P}=0.049)$ was significantly lower in DEX group than in Control group; while the percentage of patients with Stanford A $53.8 \%$ vs. $41.1 \%$, $\mathrm{P}=0.021)$, the average APACH II score $(21.01 \pm 4.68 v s$. $19.15 \pm 5.12, \mathrm{P}=0.025)$ and the average NT-pro-BNP level $(795.17 \pm 383.19$ vs. $694.23 \pm 323.57 \mu \mathrm{g} / \mathrm{mL}, \mathrm{P}=0.011)$ were significantly higher in the DEX group.

\section{Predictors associated with 7-day mortality}

In the univariate Cox hazard analysis of 7-day mortality, age $(\mathrm{P}=0.032)$, initial SBP $(\mathrm{P}<0.001)$, initial heart rate $(\mathrm{P}=0.011)$, hypertension $(\mathrm{P}<0.001)$, smoker $(\mathrm{P}<0.001)$, APACHE II score $(\mathrm{P}=0.002)$, diabetes $(\mathrm{P}=0.001)$, stanford type A $(\mathrm{P}<0.001)$, fluctuation of heart rate $(\mathrm{P}<0.001)$, fluctuation of SBP $(\mathrm{P}<0.004)$ were found to be significant factors. The multivariate Cox hazard analysis of these factors revealed that initial heart rate [hazard ratio $(\mathrm{HR})=6.866,95 \%$ confidence interval (CI): 3.236-17.300, $\mathrm{P}<0.001$ ], Initial SBP (HR=4.551, 95\% CI: 2.161-11.910, $\mathrm{P}=0.011)$, Stanford type A (HR=3.866, 95\% CI: $1.382-10.227, \mathrm{P}<0.001)$, APACHE II score (HR=4.216, 95\% CI: 3.161-15.910, $\mathrm{P}=0.002)$, fluctuation of heart rate $(\mathrm{HR}=4.34,95 \% \mathrm{CI}$ : 2.019-12.981, $\mathrm{P}=0.001)$, and fluctuation of $\mathrm{SBP}(\mathrm{HR}=4.941$, 95\% CI: 2.019-12.981, $\mathrm{P}=0.002)$, DEX (HR=6.786, 95\% CI: 3.161-16.910, $\mathrm{P}<0.001)$ were significant predictive factors for the occurrence of 7-day death (Table 2).

\section{Comparison of heart rate and SBP at different time points between the DEX and Control Groups}

As shown in Table 3, the heart rate in DEX group patients began to decrease at 1 hour after DEX infusion, but not in Control group; And at different time point of T1, T3, T6, T12, the decreasing range of heart rate in DEX group was significantly greater than that in the Control group. In addition, the early control rates of heart rate in DEX group was significantly higher than that in the Control group in the first $3 \mathrm{~h}(53.22 \%$ vs. $30.34 \%, \mathrm{P}=0.009)$, while the $24 \mathrm{~h}$ fluctuation range of heart rate in the DEX group was smaller (17.27 \pm 3.91 vs. $22.26 \pm 7.34 \mathrm{bpm}, \mathrm{P}=0.012)$. Although the SBP could be well controlled during the whole observing period and there was no difference in the control rate of SBP between two groups ( $81.34 \%$ vs. $80.28 \%$ ), the $24 \mathrm{~h}$ fluctuation range of SBP in the DEX group was significant smaller $(21.26 \pm 7.34$ vs. $31.81 \pm 8.77 \mathrm{mmHg}, \mathrm{P}=0.003)$.

\section{Comparison of clinical outcomes}

As shown in Table 4, $\beta$-receptor blocker infusion (Esmolol) was applied in both groups, but the average daily dosage of Esmolol in the DEX group was significantly lower in comparison with Control group $(2,188.54 \pm 981.48 v s$. $2,633.01 \pm 992.48 \mathrm{mg}, \mathrm{P}=0.001)$. According to clinical presentation and $\mathrm{X}$-ray tests, $8(8.79 \%)$ patients in the DEX group occurred acute pulmonary edema, which was significantly less than 75 (20.31\%) patients in the Control group $(\mathrm{P}=0.009)$. In addition, the incidence of aortic rupture in DEX group was significantly less than Control group, $11.01 \%(\mathrm{n}=10)$ vs. $20.80 \%$ ( $\mathrm{n}=77$ ), $\mathrm{P}=0.036$. Kaplan-Meier analysis indicated that pre-operative survival rates within 7 days were significantly higher in the DEX group than Control group ( $\mathrm{P}=0.03$, log-rank test) (Figure 1). 
Table 3 Changes of HR and SBP at different time points between DEX and control groups

\begin{tabular}{|c|c|c|c|c|c|c|c|c|c|}
\hline Group & TO & T1 & T3 & T6 & $\mathrm{T} 12$ & T24 & $\mathrm{T} 48$ & $\begin{array}{c}{ }^{\star} \text { Early } \\
\text { control rate }\end{array}$ & $\begin{array}{c}{ }^{\%} \text { Fluctuation } \\
\text { of HR and } \\
\text { SBP }\end{array}$ \\
\hline HR (bpm) & $115.34 \pm 13.31$ & $86.28 \pm 7.49^{a}$ & $86.01 \pm 8.12^{b}$ & $77.79 \pm 6.80^{c}$ & $73.08 \pm 4.58^{d}$ & $66.78 \pm 8.28$ & $68.16 \pm 8.23$ & $48(53.22)^{\mathrm{e}}$ & $17.27 \pm 3.91^{f}$ \\
\hline $\begin{array}{l}\text { SBP } \\
(\mathrm{mmHg})\end{array}$ & $170.18 \pm 14.77$ & $113.08 \pm 10.78$ & $113.08 \pm 10.78$ & $113.05 \pm 9.93$ & $112.62 \pm 10.84$ & $112.98 \pm 10.18$ & $114.27 \pm 10.04$ & $74(81.34)$ & $21.81 \pm 6.08^{9}$ \\
\hline \multicolumn{10}{|c|}{ Control group $(n=370)$} \\
\hline $\mathrm{HR}(\mathrm{bpm})$ & $116.72 \pm 13.86$ & $106.30 \pm 13.68$ & $106.23 \pm 13.38$ & $86.98 \pm 7.54$ & $73.24 \pm 4.41$ & $68.28 \pm 10.14$ & $68.29 \pm 12.14$ & $112(30.34)$ & $22.26 \pm 7.34$ \\
\hline $\begin{array}{l}\text { SBP } \\
(\mathrm{mmHg})\end{array}$ & $171.22 \pm 20.81$ & $113.56 \pm 10.63$ & $114.05 \pm 10.62$ & $113.05 \pm 10.82$ & $114.58 \pm 10.06$ & $114.04 \pm 9.91$ & $115.42 \pm 9.33$ & 297 (80.28) & $31.81 \pm 8.77$ \\
\hline
\end{tabular}

Continuous variables were expressed as mean $\pm \mathrm{SD}$, categorical variables were expressed as $\mathrm{n}(\%)$. DEX group was defined as patients treated with dexmedetomidine infusion, and Control group was the patients who didn't treat with dexmedetomidine infusion. T0, T1, T3, T6, T12, T24, T48 represented as at 0, 1, 3, 6, 12, 24 and $48 \mathrm{~h}$ after admission, respectively. ${ }^{\dagger}$, early control was defined as the HR or SBP was well controlled and reached the ideal goal within the first 3 hours (HR: $60-70 \mathrm{bpm}$, SBP: 100-120 mmHg, respectively). ${ }^{\S}, 24 \mathrm{~h}$ fluctuation range was defined as daily fluctuation level of $\mathrm{HR}$ or SBP after meeting to the therapeutic goal. Compared with Control group, ${ }^{\mathrm{a}} \mathrm{P}=0.032$, ${ }^{\mathrm{b}} \mathrm{P}=0.0021,{ }^{\mathrm{C}} \mathrm{P}=0.0019,{ }^{\mathrm{d}} \mathrm{P}=0.007,{ }^{\mathrm{e}} \mathrm{P}=0.009,{ }^{\mathrm{f}} \mathrm{P}=0.012,{ }^{9} \mathrm{P}=0.003$. SBP, systolic blood pressure; HR, heart rate; DEX, dexmedetomidine.

Table 4 Clinical outcomes in patients with/without dexmedetomidine infusion

\begin{tabular}{|c|c|c|c|}
\hline Outcomes & $\begin{array}{l}\text { DEX group }{ }^{a} \text {, } \\
\quad n=91\end{array}$ & $\begin{array}{l}\text { Control group }{ }^{a} \text {, } \\
\qquad n=370\end{array}$ & $\begin{array}{c}\mathrm{P} \\
\text { value }\end{array}$ \\
\hline $\begin{array}{l}\text { Average daily dos } \\
\text { of Esmolol (mg) }\end{array}$ & $38.54 \pm 981.48$ & $2,633.01 \pm 992.48$ & 0.010 \\
\hline $\begin{array}{l}\text { Acute pulmonary } \\
\text { edema }\end{array}$ & $8(8.87)$ & 75 (20.31) & 0.009 \\
\hline Aortic rupture & $10(11.01)$ & $77(20.80)$ & 0.036 \\
\hline \multicolumn{4}{|c|}{$\begin{array}{l}\text { Continuous variables were expressed as mean } \pm \text { SD and } \\
\text { categorical variables were expressed as } \mathrm{n}(\%) \text {. ", DEX group } \\
\text { was defined as patients treated with dexmedetomidine infusion, } \\
\text { and Control group was the patients who didn't treat with } \\
\text { dexmedetomidine infusion. }{ }^{b}, \mathrm{P} \text { for global comparisons among } \\
\text { groups by Kruskal-Wallis and chi-squared tests for continuous } \\
\text { and categorical variables, respectively. DEX, dexmedetomidine. }\end{array}$} \\
\hline
\end{tabular}

\section{Propensity-matched patient analysis}

Estimated propensity scores were used to match 89 patients in the DEX with 89 patients in the Control groups. The baseline clinical characteristics of included patients were not differed between groups (Table 5). According to the propensity-matched patient analysis in Table 6, the early control rates of heart rate in DEX group was significantly higher than Control group at 3-hour [53.9\% ( $\mathrm{n}=48)$ vs. $34.8 \%(\mathrm{n}=31), \mathrm{P}=0.016]$. And the $24 \mathrm{~h}$ fluctuation range of heart rate and SBP in the DEX group were significantly

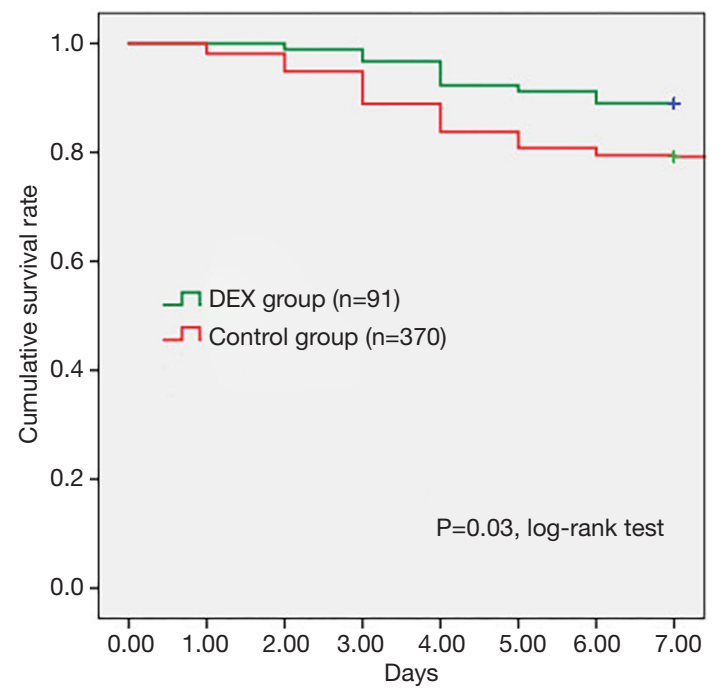

Figure 1 Kaplan-Meier survival curves comparing survival probability during 7-day following ICU admission between two groups. Kaplan-Meier analysis indicated that pre-operative survival rates within 7 days were significantly higher in patients in the DEX group than in those in the Control group ( $\mathrm{P}=0.03$, log-rank test). DEX, dexmedetomidine.

smaller $(17.30 \pm 3.94$ vs. $22.06 \pm 7.10 \mathrm{bpm}, \mathrm{P}=0.000$, and $21.73 \pm 6.03$ vs. $31.57 \pm 11.22 \mathrm{mmHg}, \mathrm{P}=0.001$. There were $7(7.9 \%)$ patients in the DEX group occurred acute pulmonary edema while 17 (19.1\%) patients in the Control 
Table 5 Baseline characteristics of the propensity-matched patients

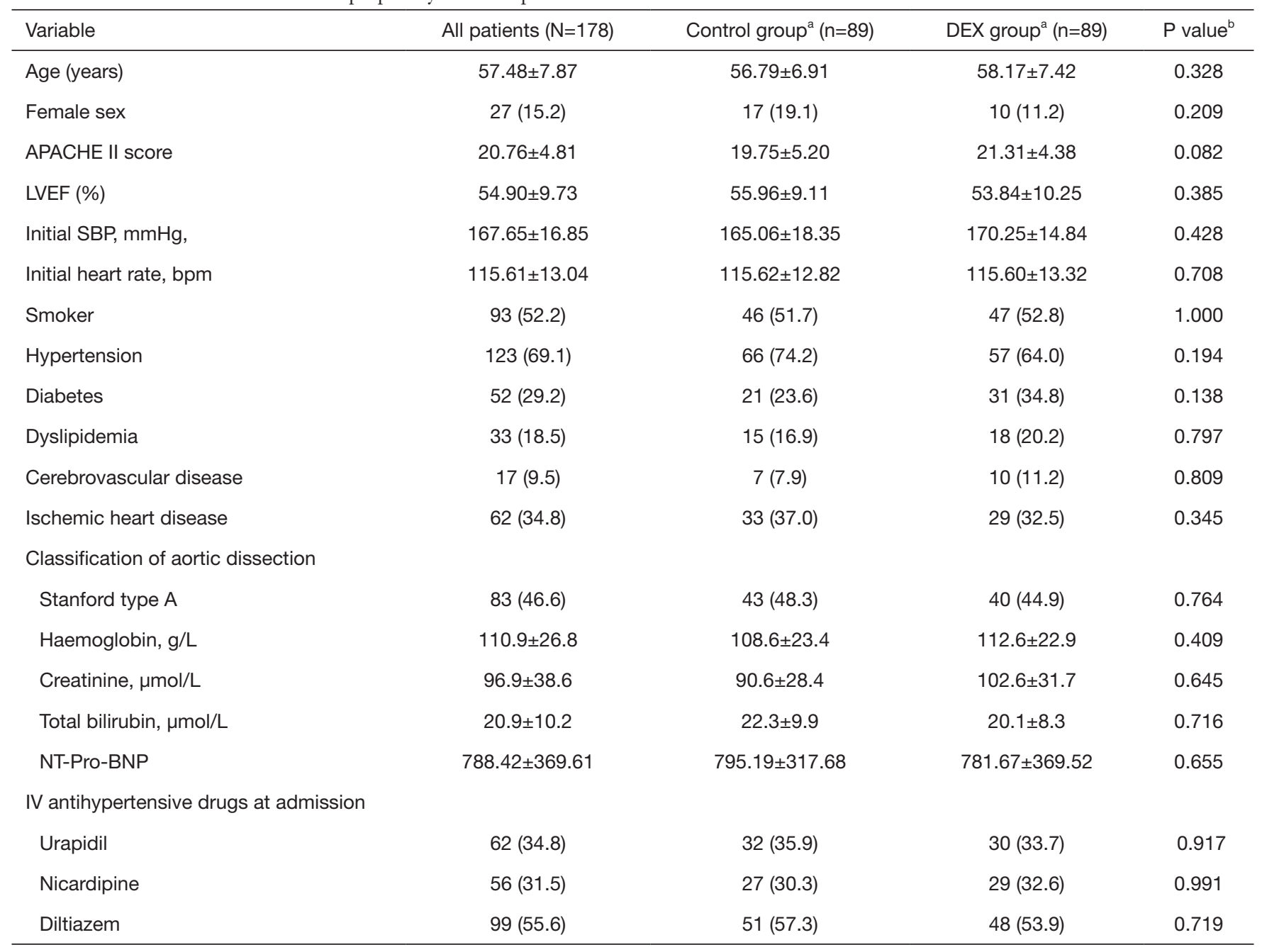

Continuous variables were expressed as mean \pm SD. Categorical variables were expressed as $n(\%) .{ }^{a}$, DEX group was defined as patients treated with dexmedetomidine infusion, and Control group was the patients who didn't treat with dexmedetomidine infusion. ${ }^{\mathrm{b}}$, P for global comparisons among groups by Kruskal-Wallis and chi-squared tests for continuous and categorical variables, respectively. APACHE II, acute physiology and chronic health evaluation II score; LVEF, left ventricular ejection fraction; NT-pro-BNP, N-terminal pro-brain natriuretic peptide; SBP, systolic blood pressure; DEX, dexmedetomidine.

group $(\mathrm{P}=0.047)$. In addition, aortic dissection rupture occurred in $8(9.0 \%)$ patients of the DEX group, and the incidence was significantly lower than that in the Control group $(24.7 \%, \mathrm{n}=22), \mathrm{P}=0.008$. Figure 2 showed that preoperative survival rates within 7 days were significantly higher in propensity-matched patients of the DEX group than the Control group $(\mathrm{P}=0.004$, log-rank test).

\section{Discussion}

In recent years, the total survival rate in patients with $\mathrm{AAD}$ has prominently improved, which indicates that more and more patients have benefited from advances in surgical approaches $(6,9,10)$. Unfortunately, the mortality rate of pre-operation is still high, which is mainly attributed to unsatisfied control of heart rate (3). In this study, the efficacy of DEX in reducing heart rate and BP was evaluated. We retrospectively analyzed data and found that DEX could facilitate more efficient and rapid heart rate control, and improve the survival rate of pre-operation in patients with $\mathrm{AAD}$.

Before surgery, controlling heart rate and BP steady is the key to prevent the rupture of aortic dissection $(8,11)$. As shown in our study, initial value of heart rate/SBP 
Table $6 \mathrm{HR} / \mathrm{SBP}$ control and clinical outcomes of the propensity-matched patients

\begin{tabular}{|c|c|c|c|}
\hline Outcomes & DEX group ${ }^{a}, n=89$ & Control group ${ }^{a}, n=89$ & $P$ value ${ }^{b}$ \\
\hline \multicolumn{4}{|l|}{${ }^{\%} 24 \mathrm{~h}$ fluctuation } \\
\hline HR (bpm) & $17.30 \pm 3.94$ & $22.06 \pm 7.10$ & 0.000 \\
\hline $\mathrm{SBP}(\mathrm{mmHg})$ & $21.73 \pm 6.03$ & $31.57 \pm 11.22$ & 0.001 \\
\hline Aortic rupture & $8(9.0)$ & $22(24.7)$ & 0.008 \\
\hline
\end{tabular}

Continuous variables were expressed as mean \pm SD and categorical variables were expressed as $n(\%) .{ }^{\dagger}$, early control was defined as the HR or SBP was well controlled and met to the ideal goal within the first 3 hours (HR: 60-70 bpm, SBP: 100-120 mmHg, respectively). ${ }^{\S}, 24$ $\mathrm{h}$ fluctuation range was defined as daily fluctuation level of HR or SBP after meeting to the therapeutic goal. ${ }^{\text {a }}$, DEX group was defined as patients treated with dexmedetomidine infusion, and Control group was the patients who didn't treat with dexmedetomidine infusion. ${ }^{\mathrm{b}}$, $\mathrm{P}$ for global comparisons among groups by Kruskal-Wallis and chi-squared tests for continuous and categorical variables, respectively. SBP, systolic blood pressure; HR, heart rate; DEX, dexmedetomidine.

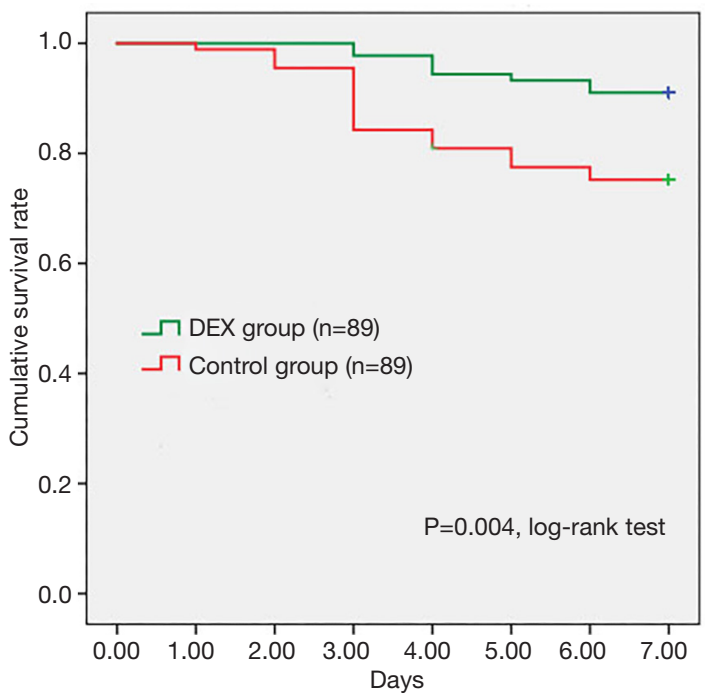

Figure 2 Kaplan-Meier analysis of cumulative survival rates in propensity-matched patients. The pre-operative survival rates within 7 days were significantly higher in propensity-matched patients of the DEX group than in those of the Control group ( $\mathrm{P}=0.004$, log-rank test). DEX, dexmedetomidine.

and fluctuation of heart rate/SBP both were significant predictive factors for the occurrence of 7-day death. However, compared with SBP, it is much more difficult to control heart rate (12). Until now, clinician still have a preference for using large amount of beta-antagonists to control the heart rate of AAD patients $(8,13)$. In fact, betaantagonists alone cannot rapidly reduce the heart rate of a considerable part of AAD patients to expected value, meanwhile, their negative inotropic effects could exacerbate symptoms in heart dysfunction patients and even induce acute heart failure (14). Therefore, finding a new solution to control heart rate is urgently needed.

The onset of aortic dissection would induce a series of inflammatory and stress responses (15). DEX is a highly selective alpha-2 adrenergic agonist which could effectively inhibit the production of stress-related catecholamine (16). Previous clinical use of DEX as a sedative agent also showed its side effect in reducing heart rate $(17,18)$. The role of DEX in lowering catecholamine level and reducing heart rate seems to provide us with a new treatment idea. But almost no investigation has focused on the use of DEX as an adjunctive therapy for $\mathrm{AAD}$ patients.

In our study, patients who received regular regimens and an additional DEX therapy started to decrease heart rate $1 \mathrm{~h}$ later, while non-DEX patients began to decrease heart rate prominently $3 \mathrm{~h}$ later. In the meantime, the early control rates of heart rate in DEX group were significantly higher than Control group in the first $3 \mathrm{~h}(53.22 \%$ vs. $30.34 \%$, $\mathrm{P}=0.009$ ). Furthermore, the degree of heart rate slowdown was significantly greater in the DEX group than non-DEX group at 6,12 and $24 \mathrm{~h}$ after admission. This indicated that the combination of DEX and beta-receptor antagonist could provide faster heart rate control.

The data also showed that patients in both groups met the predefined SBP easily and had high early control rates of SBP, which was similar to previous clinical research (19). Meanwhile, the SBP could be well controlled during the first $3 \mathrm{~h}$ and there was no significant difference between two groups (81.34\% vs. 80.28\%). Although the SBP could 
be well controlled during the whole observation period and there was no difference in the control rate of SBP between the two groups, after reaching the ideal SBP, the $24 \mathrm{~h}$ fluctuation range of SBP in the DEX group was smaller (21.26 \pm 7.34 vs. $31.81 \pm 8.77 \mathrm{mmHg}, \mathrm{P}=0.003)$. Therefore, DEX could facilitate more efficient and rapid heart rate control, and keep BP more stable.

Some investigations have reported that AAD can induce an urgent complication-acute pulmonary edema, which is considered as the combinational results of severe inflammatory responses, overused beta-antagonist, and preexisting heart disease $(20,21)$. Our study figured out that the incidence rate of acute pulmonary edema in DEX group was significantly lower than Control group (8.79\% vs. $20.31 \%, \mathrm{P}=0.009)$, and less daily dosage of Esmolol $(2,188.54 \pm 981.48$ vs. $2,633.01 \pm 992.48 \mathrm{mg}, \mathrm{P}=0.001)$ in DEX group seems to be a positive factor. In the meantime, the occurrence rate of aortic rupture in DEX group was $11.01 \%$, which reduced significantly in comparison with Control group (20.80\%) ( $\mathrm{P}=0.036)$. Our Kaplan-Meier analysis indicated that pre-operative survival rates within 7 days were significantly higher in patients in the DEX group than the Control group $(\mathrm{P}=0.03)$. Furthermore, estimated propensity scores were used to eliminate selection bias, we concluded that patients with additional DEX treatment had higher early control rates of heart rate, smaller $24 \mathrm{~h}$ fluctuation range of heart rate and SBP, lower incidence rates of acute pulmonary edema and aortic dissection rupture, higher pre-operative survival rates.

In conclusion, these results regarding protective efficacy of DEX against AAD patients were validated. DEX could trigger faster and more efficient heart rate control, reduce the total amount of beta-antagonist usage, decrease the incidence of complications, keep BP in a more stable status, and increase pre-operative survival rate, which is consistent with its function in anti-sympathetic activation, antiinflammatory responses and bradycardia.

Even though our study is not a prospective trail, we still provide new thinking for clinicians. There are, however, limitations mainly inherent to the single-center retrospective study design with limited sample size and another well designed double-blind, multi-center trial is waiting to be conducted.

\section{Acknowledgments}

The authors are grateful to Deng Yi-Yu for illustration design. We also thank Clinical Trial Center of Guangdong
Provincial People's Hospital for statistical consultation and support.

Funding: This study was supported by National Natural Science Foundation of China (Grant No. 81701875) and Science and Technology Program of Guangzhou, China (Grant No. 201904010039).

\section{Footnote}

Reporting Checklist: The authors have completed the STROBE reporting checklist. Available at http://dx.doi. org/10.21037/apm-20-363

Data Sharing Statement: Available at http://dx.doi. org/10.21037/apm-20-363

Conflicts of Interest: All authors have completed the ICMJE uniform disclosure form (available at http://dx.doi. org/10.21037/apm-20-363). The authors have no conflicts of interest to declare.

Ethical Statement: The authors are accountable for all aspects of the work in ensuring that questions related to the accuracy or integrity of any part of the work are appropriately investigated and resolved. This study was conducted in accordance with the Declaration of Helsinki (as revised in 2013) and was approved by the Ethics Committee of the Guangdong Provincial People's Hospital (No. GDREC2018162H) and individual consent for this retrospective analysis was waived.

Open Access Statement: This is an Open Access article distributed in accordance with the Creative Commons Attribution-NonCommercial-NoDerivs 4.0 International License (CC BY-NC-ND 4.0), which permits the noncommercial replication and distribution of the article with the strict proviso that no changes or edits are made and the original work is properly cited (including links to both the formal publication through the relevant DOI and the license). See: https://creativecommons.org/licenses/by-nc-nd/4.0/.

\section{References}

1. Nienaber CA, Powell JT. Management of acute aortic syndromes. Eur Heart J 2012;33:26-35b.

2. Nienaber CA, Eagle KA. Aortic dissection: New frontiers in diagnosis and management: Part I: From etiology to diagnostic strategies. Circulation 2003;108:628-35. 
3. Yamaguchi T, Nakai M, Sumita Y, et al. Current status of the management and outcomes of acute aortic dissection in Japan: Analyses of nationwide Japanese Registry of All Cardiac and Vascular Diseases-Diagnostic Procedure Combination data. Eur Heart J Acute Cardiovasc Care 2019. [Epub ahead of print].

4. Howard DP, Banerjee A, Fairhead JF, et al. Populationbased study of incidence and outcome of acute aortic dissection and premorbid risk factor control: 10-Year results from the Oxford Vascular Study. Circulation 2013;127:2031-7.

5. Evangelista A, Isselbacher EM, Bossone E, et al. Insights from the International Registry of Acute Aortic Dissection: A 20-year experience of collaborative clinical research. Circulation 2018;137:1846-60.

6. Evangelista A, Rabasa JM, Mosquera VX, et al. Diagnosis, management and mortality in acute aortic syndrome: Results of the Spanish Registry of Acute Aortic Syndrome (RESA-II). Eur Heart J Acute Cardiovasc Care 2018;7:602-8.

7. Su X, Meng ZT, Wu XH, et al. Dexmedetomidine for prevention of delirium in elderly patients after noncardiacsurgery: a randomised, double-blind, placebocontrolled trial. Lancet 2016;388:1893-902.

8. Erbel R, Aboyans V, Boileau C, et al. 2014 ESC Guidelines on the diagnosis and treatment of aortic diseases: Document covering acute and chronic aortic diseases of the thoracic and abdominal aorta of the adult. The Task Force for the Diagnosis and Treatment of Aortic Diseases of the European Society of Cardiology (ESC). Eur Heart J 2014;35:2873-926.

9. Okita Y. Current surgical results of acute type A aortic dissection in Japan. Ann Cardiothorac Surg 2016;5:368-76.

10. Chikwe J, Cavallaro P, Itagaki S, et al. National outcomes in acute aortic dissection: Influence of surgeon and institutional volume on operative mortality. Ann Thorac Surg 2013;95:1563-9.

Cite this article as: Chen SL, Chai YF, Wang ZH, Liu XQ, Ding HG, Zeng HK. Effects of dexmedetomidine on heart rate control and pre-operative outcome in patients with acute aortic dissection: a propensity-matched analysis. Ann Palliat Med 2020;9(5):2886-2894. doi: 10.21037/apm-20-363
11. Hagan PG, Nienaber CA, Isselbacher EM, et al. The International Registry of Acute Aortic Dissection (IRAD): New insights into an old disease. JAMA 2000;283:897-903.

12. Sokolov VV, Rubtsov NV, Redkoborodyı̆ AV, et al. Choice of optimal treatment policy in patients with descending aortic dissection. Angiol Sosud Khir 2019;25:115-9.

13. Kaji S. Acute medical management of aortic dissection. Gen Thorac Cardiovasc Surg 2019;67:203-7.

14. Takagi H, Ando T, Umemoto T, et al. Meta-Analysis of Seasonal Incidence of Aortic Dissection. Am J Cardiol 2017;120:700-7.

15. Luo F, Zhou XL, Li JJ, et al. Inflammatory response is associated with aortic dissection. Ageing Res Rev 2009;8:31-5.

16. Cummings BM, Cowl AS, Yager PH, et al. Cardiovascular Effects of Continuous Dexmedetomidine Infusion Without a Loading Dose in the Pediatric Intensive Care Unit. J Intensive Care Med 2015;30:512-7.

17. Luthra A, Prabhakar H, Rath GP. Alleviating Stress Response to Tracheal Extubation in Neurosurgical Patients: A Comparative Study of Two Infusion Doses of Dexmedetomidine. J Neurosci Rural Pract 2017;8:S49-56.

18. Su F, Nicolson SC, Zuppa AF. A dose-response study of dexmedetomidine administered as the primary sedative in infants following open heart surgery. Pediatr Crit Care Med 2013;14:499-507.

19. Suzuki T, Isselbacher EM, Nienaber CA, et al. Typeselective benefits of medications in treatment of acute aortic dissection (from the International Registry of Acute Aortic Dissection [IRAD]). Am J Cardiol 2012;109:122-7.

20. Jo Y, Anzai T, Sugano Y, et al. Early use of beta-blockers attenuates systemic inflammatory response and lung oxygenation impairment after distal type acute aortic dissection. Heart Vessels 2008;23:334-40.

21. Lien WC, Wang CH, Chang WT, et al. Aortic dissection presenting with acute pulmonary edema. Am J Emerg Med 2018;36:1323.e7-9. 